\title{
Study on Anatomy and Powder Microscopy of Roots of Sida Alnifolia Linn - Bala of Kerala
}

\author{
${ }^{1}$ Ashima K. Sasidharan , ${ }^{2}$ Dr.P.Y Ansari \\ ${ }^{1}$ PG Scholar, Department of Dravyagunavijnanam, Government Ayurveda College, Tripunithura, \\ Ernakulam, Kerala,India \\ ${ }^{2}$ Professor and HOD, Department of Dravyagunavijnanam, Government Ayurveda College, Tripunithura, \\ Ernakulam, Kerala,India
}

\begin{abstract}
The genus Sida L., belonging to family Malvaceae is a therapeutically important genus. The different species of which are widely used in traditional systems of medicine throughout India. This genus is of great importance in the Indian traditional system of medicine and this is perhaps the most widely used raw drug in the production of different Ayurvedic formulations in the name Bala. Northern authors consider Bala as Sida cordifolia Linn, but in Kerala,particular variety Sida alnifolia Linn. is taken as Kurunthotti and used under the label of Bala. It is commonly used as the drug Bala by both the traditional and Ayurvedic practitioners of Kerala. This particular variety is mentioned in Hortus Malabaricus, the text book which deals with the medicinal plants of Kerala. Importantly the drug Bala is not mentioned in Ayurvedic pharmacopeia of India; still it is a widely used drug for many preparations of Ayurveda. Since it is used as Bala in Kerala, the references available for its identification are a few, the taxonomy and histological parameters including powder microscopy of the root presented in this paper may be proposed as parameters to identify and establish the authenticity of root of Sida alnifoia Linn.
\end{abstract}

Keywords: Bala, histological parameters, Kurunthotti, Sida alnifolia Linn, taxonomy, powder microscopy.

\section{INTRODUCTION}

Sida is a large genus with about 200 species distributed throughout the world and 17 are reported to occur in India ${ }^{1}$. This genus is of great importance in the Indian traditional system of medicine and this is perhaps the most widely used raw drug in the production of different Ayurvedic formulations. Among these, S. alnifolia is widely used in Ayurveda as well as in Indian folklore and traditional medicine.

The root of this plant is extensively accepted as the source plant of the renowned Ayurvedic drug 'Bala' locally known as 'Kurunthotti', in Kerala. Bala in Sanskrit, commonly known as Kurunthotti in Malayalam is a popular drug used in various Ayurvedic formulations used especially in Rheumatic complaints. The name Bala indicates that the plant which is strong itself and increases Bala (strength) of the body. This drug is one of the medicaments used in the treatment of various ailments such as Vathavuadhi having some neurological impairment (hemiplegia, facial palsy), tuberculosis, diabetes and uterine disorders. There are so many important Ayurvedic formulations that contain this drug in the form of Kashaya, thaila, Gritha, choorna etc are available in the market.

Precise morphological description regarding the identity of drug Bala is not available in Ancient classical text books. Synonyms and therapeutic indications mentioned in classical texts give us the knowledge regarding the properties but not about the genuine source of Bala. A number of plants of Sida genus are equated with its identity in different parts of country. 
Hortus malabaricus, a comprehensive treatise that portrays the medicinal plants of Kerala describes the morphological characters and therapeutic uses of this drug under the name Kurundoti ${ }^{2}$. The first recorded picture of this drug which helps to identify that the drug used as Kurunthotti in Kerala is Sida alnifolia Linn since we are getting the other botanical sources in the label of Bala. A previous study showed that the demand of Sida root is increased to 1194 tons per year by the Ayurvedic drug manufacturing industry in Kerala $^{3}$. The earlier reports revealed bulk requirement of this drug in health care industry of the country. The drug Bala is collected from wild and there are no organized cultivation practices ${ }^{4}$. So the chances of adulteration are very high in this case then the methods of identification of the drug have become very significant. There were some studies to ascertain the identity of the genuine drug Bala, through root anatomy of selected species of Sida. But these studies do not eliminate the doubts regarding the drug, since the packets of kashaya sookshma choornas (fine powder of kashaya) readily available in the market. So the role of the powder microscopy turns relevant here in order to ensure the presence of the drug even in the combination drugs. So this study helps to confirm the genuineness of plants and raw drugs hence can prevent adulteration and substitution and thus aids in quality control of finished products.

In the present study the anatomical evaluation of the root of Bala, Sida alnifolia Linn. has been conducted macroscopically and microscopically as well as the powder microscopy. The studies were conducted in pharmacognosy unit, department of Dravyagunvijnana, Government Ayurveda College Tripunithura.

\section{MATERIALS AND METHODS}

Collection of plant material

The fresh plants of Bala, Sida alnifolia Linn.were collected from Tripunithura locality of Ernakuam district. Specimens of all the species were collected studied their morphology, compared with authenticated specimens and determined their taxonomic identity.

\section{PHARMACOGNOSTIC EVALUATION}

\section{Macroscopic features}

The macroscopic evaluation (morphological parameters) features of fresh root of Bala, Sida alnifolia Linn. carried out to identify and to establish the genuineness. Materials used are Magnifying lens, dissecting microscope and digital camera.

\section{Procedure}

The collected roots were washed and dried and were subjected to identification with naked eyes and by tactile and other sensory inspections. The macroscopic features of the collected sample drug were then compared with that of the description of root of Bala Sida alnifolia Linn.available in authentic pharmacognosy text books. The macroscopic characters of the officinal part root were studied and the results were tabulated.

\section{Microscopic features}

The microscopic evaluations of fresh root of Bala, Sida alnifolia Linn. carried out to identify and to establish the genuineness with the help of microscopic evaluation (histological parameters). Materials used are Razor or safety razor blade, dissecting needles, watch glasses, petry dishes, glass slides, cover slips 3/4 circles (No. 2 thickness), camel hair brush (medium size), dropper, safranine stain, glycerine, compound microscope, digital camera.

\section{Procedure}

Fine handmade transverse sections of fresh root of Bala, Sida alnifolia Linn. was made with the help of razor blade. Free hand sections were taken and a thin uniformly cut section was selected and suspended in water 
in a watch glass. After that a few drops of safranine stain was added to the water containing thin section. The section was washed with distilled water until no traces of stain came off in the water.it was then transferred on a clean slide with help of a hair brush. The stained section was mounted at the centre of the slide and a drop of glycerin water was added on the section. Then it was covered with a cover slip without getting air bubble between the slide and cover.

The prepared stained slide was placed on the stage of the compound microscope and fixed it with the clips. The light was focused to mounted slide by using the mirror. After this the lens was adjusted at a power of $10 \mathrm{X}$ for visualizing the histological parameters of the sample. Then the power was adjusted to $40 \mathrm{X}$ for getting finer details of the histological parameters. Photographs of the sections were taken using a digital camera at 10x and 40x powers. The anatomical studies of the plants were done and the photographs were taken.

\section{Powder Macroscopy}

Fine powder dried root powder of Bala, Sida alnifolia Linn. were placed on white paper and viewed using magnifying lens and naked eye. Texture of the powders was assessed using fingers. There after the powders were smelled and tasted to determine the odour and taste. The results were tabulated.

\section{b) Powder microscopy}

To identify and to establish the genuineness of dried root powder of Bala, Sida alnifolia Linn. with the help of powder microscopic features. So the powder microscopic study gives the anatomical characters of the fragmented crude drugs.

Materials used were watch glass, glass slide, cover slips, 3/4 circles (no: 2 thickness), camel hair brush (medium sized), compound microscope, digital camera.

\section{Procedure}

A pinch of fine powder of sample drug was taken and placed on glass slide. Few drops of water was added and mixed with hair brush. This mixture was then spread throughout the glass slide so as to overcome the overlapping of constituents of various structures. Cover slip was placed on the glass slide and it was then viewed using compound microscope under 10X powers. Images were then obtained using digital camera.

The root powder of Bala was greyish in colour. Under microscopical examination, the powder shows the cortical parenchyma cells, pitted vessels, Xylem fibre,phloem fibre, Starch, rosette crystals, starch gains, Fragment of tracheid group and pitted vessels. The photographs of the microscopical view were taken.

\section{RESULTS AND DISCUSSION}

The present work encloses studies on macroscopic characters, histological parameters, powder microscopical analysis of roots of Sida alnifolia Linn.

\section{Morphological characters of the plant specimen}

The plant is an erect, herbs or undershrub of height 30-90cms high with low and strongly branched. Tap root system consists of the main tap root $(3-10 \mathrm{~mm}$ dia)and many branching lateral roots with yellowish brown colour. These have a large number of wiry rootlets. Branches- densely intricate,woody and solid. LeavesRamal, alternate, Petiolate , short petioled, about 3mm or less, Stipulate. Leaf base: - cuneate; Kind: simple; Form of lamina: - shape and size varies according to the age of the plant. In Seedlings \& young plants leaves obovate. Margin:- coarsely toothed towards the apex; Apex- truncate or retuse tip ;nearly glabrous above but hairy tomentose beneath, reticulate venation and dark green Inflorescences are solitary axillary peduncles, staminate, pistillate, Yellow fading to white,.Calyx without any epicalyx, gamosepalous, persistent, broadly companulate, 5 angular,5 lobed, lobe triangular acute, Aestivation-valvate in bud. Schizocarp $4 \mathrm{~mm}$ long, Type-small and enclosed with in the calyx. The carpels when ripe are reticulated 
each having 2 short awns about as long as themselves. They separate from each other and from the central axis as the indehiscent 1 -seeded cocci.

\section{Macroscopic features}

The macroscopic features of the drug were studies and compared with the details in Textbook of pharmacognosy of Ayurvedic drugs written by Prof. Narayana Aiyer and M. Kolammal. The results were given in table no:1

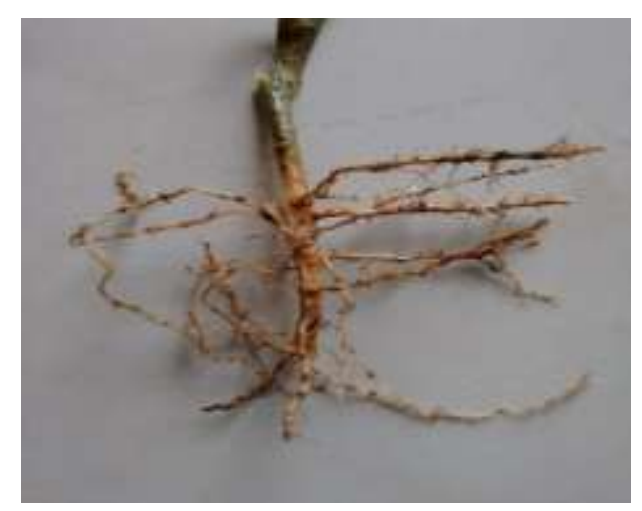

Fig .No.1. Root morphology of Sida alnifolia Linn.

Table no: 1 Organoleptic characters of fresh root of Sida alnifolia Linn.

\begin{tabular}{|c|l|}
\hline Size & $8-10 \mathrm{~mm}$ diameter \\
\hline Shape & $\begin{array}{l}\text { Cylindrical and has a number of long wavy thin lateral roots. These have a large } \\
\text { number of wiry rootlets. }\end{array}$ \\
\hline $\begin{array}{c}\text { External } \\
\text { characters }\end{array}$ & $\begin{array}{l}\text { Few very small, tangentially elongated slightly prominent lenticels on the upper part } \\
\text { of the thick root. The outer surface is not smooth due to the presence of many rootlets. }\end{array}$ \\
\hline Colour & Yellowish brown \\
\hline Odour & pleasant odour \\
\hline Taste & Sweet, slightly bitter \\
\hline
\end{tabular}

\section{Microscopic features}

$\mathrm{T} \mathrm{S}$ of the root is more or less circular in outline with wavy margin.Cork is the outermost layer and it consist of very thin and composed of 4-7 rows of thin walled, rectangular tangentially elongated cells with some of the outer cells detached and recurved. Below this layer single row of narrow Phellogen, thin walled, tangentially elongated cells. Next to this layer two or three rows of thin walled phelloderm cortex consists of bast or phloem fibres occurs in conical strands are more narrow and linear. These strands are separated by the medullary rays. Each conical strand of bast is composed of 9-11 rows of tangential strips. Smaller groups of cells are seen towards periphery and larger groups are seen towards inner side.fibre cells are long and thick walled Some phloem parenchyma cells contain small crystals of calcium-oxalate.

Inner to the phloem is the cambium, which is formed of one or two rows of narrow, thin walled cells. The innermost portion, wood forms the major part of the root is composed of mostly of secondary elements. The wood is composed of vessels, parenchyma, fibres and medullary rays. Groups of wood fibres are present almost in concentric rings alternating with groups of xylem parenchyma cells. Medullary rays are many, long, uniseriate as well as biseriate and almost straight. Extend from the centre to the periphery in the wood are radially rectangular, thick walled and packed with small compound starch grains. The ray cells of the bark are thin walled. 


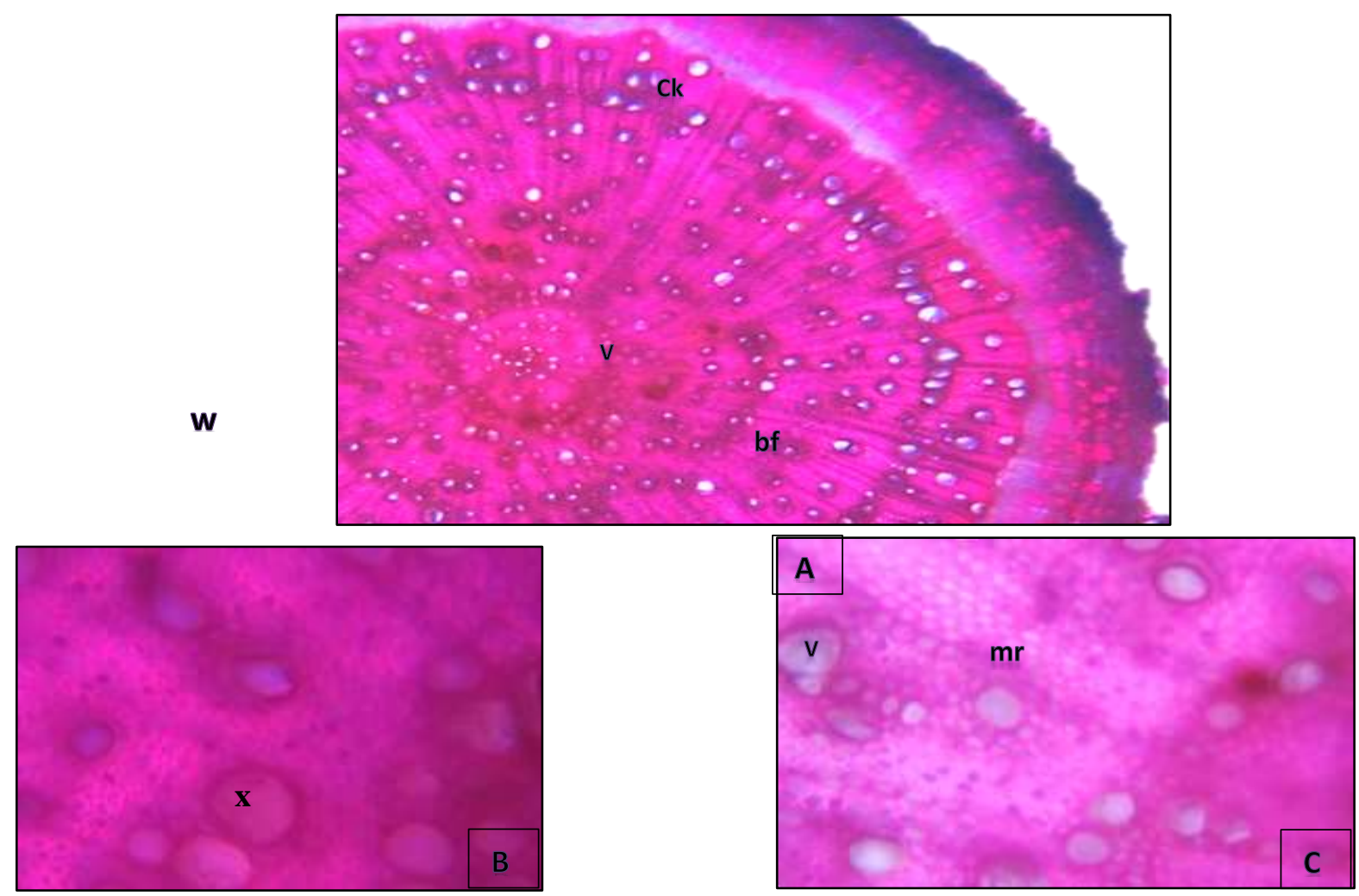

Fig no 2. Histology of T.S of fresh root of Sida alnifolia Linn. (10x) [A]T.S of root (10x) [B] \& [C] wood portion enlarged (40x).ck- cork, v-vessel, bf - bast fibre, mr- medullary ray, w- wood, x- xylem.

\section{Powder microscopy}

\section{Powder characters}

The organoleptic characters of powdered specimen were observed and the results were tabulated in table 2

Table No :2 Organoleptic characters of powder of Sida alnifolia Linn

\begin{tabular}{|c|c|}
\hline Features & Dried root powder of Bala, Sida alnifolia Linn. \\
\hline Colour & Greyish green \\
\hline Texture & Granular \\
\hline Odour & Pleasant odour \\
\hline Taste & Sweet \\
\hline
\end{tabular}

\section{Powder microscopy}

Under microscopical examination, the powder shows the cortical parenchyma cells, pitted vessels, Xylem fibre,phloem fibre, Starch, rosette crystals, starch gains, Fragment of tracheid group and pitted vessels. The photographs were taken and shown in the figure number 2

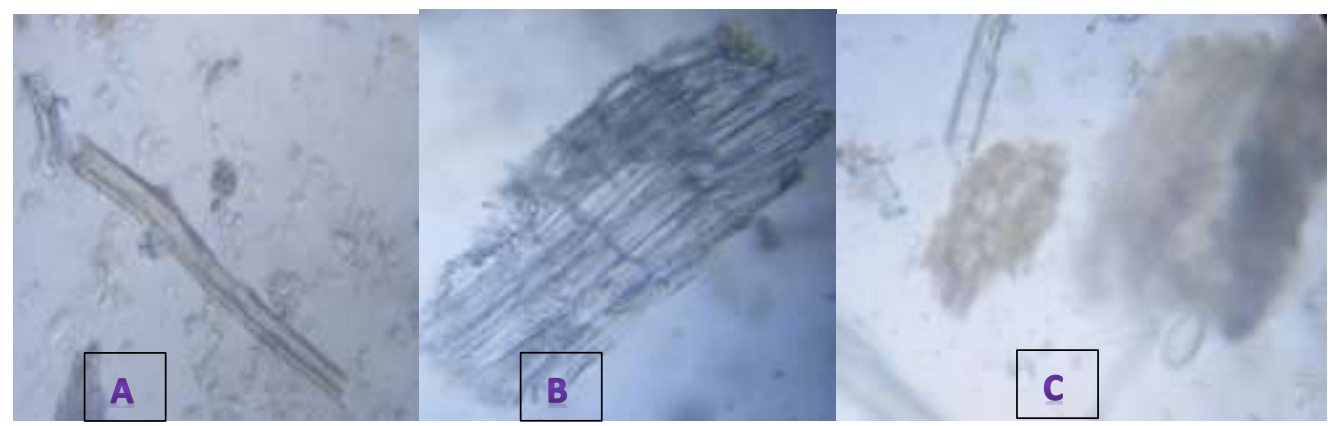




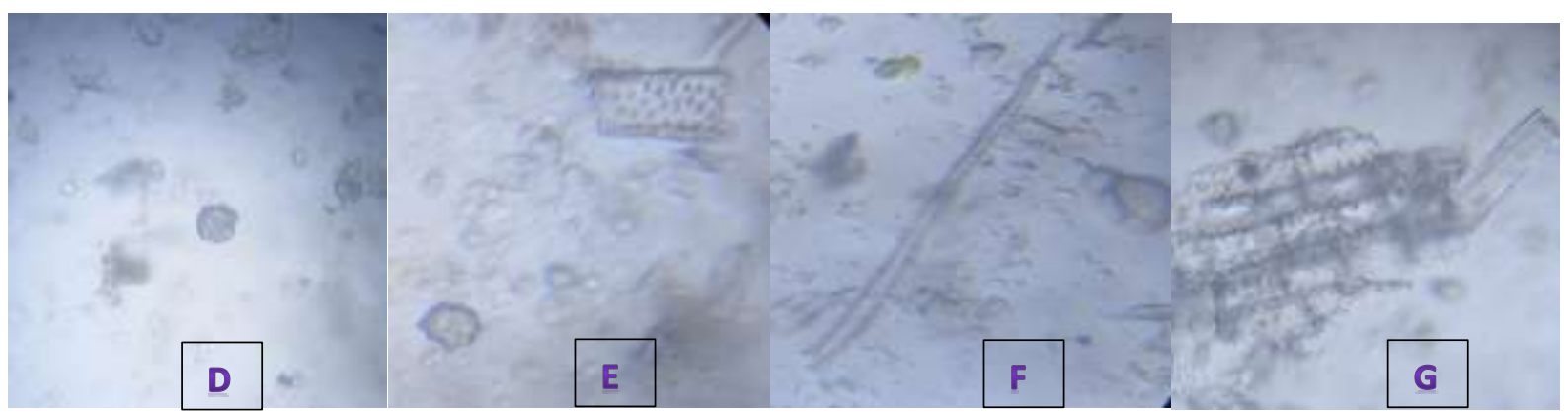

Figure no:- 2. A fibres B. phloem C. cortical parenchyma cells D. starch crystals E.pitted vessels, F. long fibers, G. fragment of tracheid group.

\section{Conclusion}

Evaluation of the crude drug is an integral part of establishing correct identity of the drug. Pharmacognostical parameters are necessary for the confirmation of the identity of the crude drug. This anatomical and powder microscopic evaluation of roots of Sida alnifolia Linn. is useful for setting standards for identification and authentication of the drug not only in crude form but also in finished products.

\section{Acknowledgement}

I express my sincere thanks to my guide Dr. P.Y. Ansary, Professor and HOD, Department of Dravyagunavijnanam, Govt. Ayurveda College, Tripunithura for expert guidance, constant encouragement and timely help rendered from the very beginning. I am also thankful to the Department faculties Dr.Sara Monsy Oommen, Dr.Shincy Mol VV and Dr.Sariga K S for their valuable suggestions.

\section{References}

1. Sivarajan VV, Pradeep KA, Malvaceae of Southern Peninsular India: A taxonomic monograph Daya Publishing House, New Delhi. 1996

2. Manilal K S. Hortus Malabaricus- Volume 8. Thiruvananthapuram: Kerala University; 2008.

3. Sasidharan N, Muraleedharan PK. The Raw Drug Requirement of Ayurvedic Medicine Manufacturing Industry in Kerala. Peechi, Thrissur: Kerala Forest Research Institute; 2009.

4. M. Navas et al. / Pharmacognosy Journal 5 (2013) 269e274. 